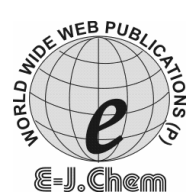

\title{
Acoustical Studies on Molecular Interactions in Binary Liquid Mixtures at $303 \mathrm{~K}$
}

\author{
R.UVARANI* and J. SIVAPRAGASAM \\ Department of Physics, K.S.R.College of Engineering, \\ Tiruchengode, Namakkal, Tamilnadu, India. \\ anbuuva@yahoo.co.in
}

Received 26 February 2009; Accepted 4 April 2009

\begin{abstract}
Molecular interaction studies using ultrasonic technique in the binary liquid mixtures of cyclohexanone with $o$-cresol and $p$-cresol have been carried out at $303 \mathrm{~K}$. Using the measured values of ultrasonic velocity, density and viscosity, acoustical parameters and their excess values are evaluated. From the properties of these excess parameters the nature and strength of the interactions in these binary systems are discussed.
\end{abstract}

Keywords: Ultrasonic velocity, Acoustical parameters, Binary mixtures.

\section{Introduction}

In recent years, ultrasonic technique has become a powerful tool for studying the molecular behaviour of liquid mixtures ${ }^{1-3}$. This is because of its ability of characterizing physicochemical behaviour of liquid medium ${ }^{4-6}$. The measurement of ultrasonic velocity have been adequately employed in understanding the molecular interactions in liquid mixtures. Molecular interaction studies can be carried out by both spectroscopic ${ }^{7,8}$ and nonspectroscopic $^{9,10}$ techniques. However, ultrasonic velocity ${ }^{11}$ and viscosity ${ }^{12}$ measurements have been widely used in the field of interactions and structural aspect evaluation studies.

\section{Experimental}

The ultrasonic velocity was measured at $303 \mathrm{~K}$ using a single crystal interferometer with a high degree of accuracy operating at a frequency of $2 \mathrm{MHz}$. The density was measured at $303 \mathrm{~K}$ using specific gravity bottle by the standard procedure and the viscosity was measured at $303 \mathrm{~K}$ using Ostwald's viscometer with an accuracy of $\pm 0.001 \mathrm{Nsm}^{-2}$.

\section{Results and Discussion}

The acoustical parameters such as adiabatic compressibility $(\beta)$, free length $\left(\mathrm{L}_{\mathrm{f}}\right)$ and free volume $\left(\mathrm{V}_{\mathrm{f}}\right)$ were calculated using the following relations,

$$
\begin{aligned}
& \beta=1 / \mathrm{U}^{2} \rho \\
& \mathrm{L}_{\mathrm{f}}=\mathrm{k}(\beta)^{1 / 2}
\end{aligned}
$$




$$
\mathrm{V}_{\mathrm{f}}=\left(\mathrm{M}_{\mathrm{eff}} \mathrm{U} / \eta \mathrm{k}\right)^{3 / 2}
$$

The excess values are calculated using the formula,

$$
A^{E}=A_{\exp }-A_{i d}
$$

Where, $A_{i d}=\sum A_{i} X_{i}$, where $A_{i}$ is any acoustical parameter and $X_{i}$ is the mole fraction of liquid component.

Table 1 shows the values of ultrasonic velocity $(\mathrm{U})$, density $(\rho)$, viscosity $(\eta)$ and excess adiabatic compressibility $\left(\beta^{\mathrm{E}}\right)$, excess free length $\left(\mathrm{L}_{\mathrm{f}}^{E}\right)$, excess free volume $\left(\mathrm{V}_{\mathrm{f}}^{E}\right)$ for cyclohexanone $+o$-cresol, $p$-cresol at $303 \mathrm{~K}$. From the Table 1 , it is observed that as the concentration of cyclohexanone increases the ultrasonic velocity decreases for both the systems studied.

As shown in Table $1, \beta^{\mathrm{E}}$ values are negative which suggest the presence of hydrogen bonding interaction between the components of the liquid mixtures. However, $\beta^{\mathrm{E}}$ values are less negative for the $o$-cresol system than that of $p$-cresol system. This indicates that the less interaction in the former system. The possible reason may be as follows, in $o$-cresol, the closeness of $-\mathrm{CH}_{3}$ to $-\mathrm{OH}$ group shows the presence of two types of effect. One is the increase of electron density in the $\mathrm{O}-\mathrm{H}$ bond and the other is the steric effect. These two effects decrease the strength of the intermolecular hydrogen bond formation in $o$-cresol than in $p$-cresol ${ }^{13}$.

Table 1. Experimental values of ultrasonic velocity $(U)$, density $(\rho)$, viscosity $(\eta)$ and excess values of adiabatic compressibility $\left(\beta^{\mathrm{E}}\right)$, free length $\left(\mathrm{L}_{\mathrm{f}}^{E}\right)$, free volume $\left(\mathrm{V}_{\mathrm{f}}^{E}\right)$ for

\begin{tabular}{|c|c|c|c|c|c|c|}
\hline $\mathrm{X}_{1}$ & $\begin{array}{c}\mathrm{U} \\
\mathrm{ms}^{-1}\end{array}$ & $\begin{array}{c}\rho \\
\mathrm{kg} \mathrm{m}^{-3}\end{array}$ & $\begin{array}{c}\eta \\
\times 10^{-3} \mathrm{Nsm}^{-2} \\
\end{array}$ & $\begin{array}{c}\beta^{\mathrm{E}} \\
\times 10^{-11} \mathrm{~N}^{-1} \mathrm{~m}^{2} \\
\end{array}$ & $\begin{array}{c}\mathrm{L}_{\mathrm{f}}^{E}, \\
\times 10^{-12} \mathrm{~m} \\
\end{array}$ & $\begin{array}{c}\mathrm{V}_{\mathrm{f}}^{E} \\
\times 10^{-7} \mathrm{~m}^{3} \mathrm{~mol}^{-1} \\
\end{array}$ \\
\hline \multicolumn{7}{|c|}{ Cyclohexanone $+o$-cresol } \\
\hline 0.1999 & 1465.8 & 1014.4 & 6.265 & -0.424 & -0.146 & -0.074 \\
\hline 0.4000 & 1445.3 & 994.8 & 5.227 & -0.506 & -0.156 & -0.124 \\
\hline 0.5000 & 1436.9 & 984.6 & 4.472 & -0.599 & -0.193 & -0.126 \\
\hline 0.6000 & 1425.1 & 972.6 & 3.853 & -0.318 & -0.069 & -0.121 \\
\hline 0.8002 & 1402.9 & 955.7 & 2.913 & -0.101 & -0.003 & -0.090 \\
\hline \multicolumn{7}{|c|}{ Cyclohexanone $+p$-cresol } \\
\hline 0.1998 & 1454.2 & 1007.8 & 8.734 & -0.528 & -0.205 & -0.065 \\
\hline 0.4001 & 1443.7 & 991.5 & 5.878 & -1.095 & -0.438 & -0.104 \\
\hline 0.4998 & 1435.2 & 981.2 & 4.818 & -1.017 & -0.397 & -0.108 \\
\hline 0.6002 & 1424.3 & 972.4 & 4.003 & -0.826 & -0.311 & -0.104 \\
\hline 0.8000 & 1404.2 & 953.5 & 2.898 & -0.356 & -0.118 & -0.070 \\
\hline
\end{tabular}
cyclohexanone $+o$-cresol, $p$-cresol at $303 \mathrm{~K}$.

The intermolecular free length $\mathrm{L}_{\mathrm{f}}$ has been calculated by using semi-empirical relation given by Jacobson ${ }^{14}$. Since $\mathrm{L}_{\mathrm{f}}$ is a derived parameter from $\beta$, the trends in the variation of $\mathrm{L}_{\mathrm{f}}{ }^{E}$ exhibit more or less similar pattern as that of $\beta^{\mathrm{E}}$ values. In general, system exhibiting specific interactions, the free length should decrease resulting in negative $\mathrm{L}_{\mathrm{f}}^{E}$ values. From Table 1 , it is observed that $\mathrm{L}_{\mathrm{f}}^{E}$ and $\mathrm{V}_{\mathrm{f}}^{E}$ values are negative at all concentrations which indicate the existence of intermolecular interactions between the components ${ }^{15}$.

\section{References}

1. Nikam P S Jagdale B S Sawant A B and Mehdi Hasan, Indian J Pure Appl Phys., 2001, 39, 433.

2. Shipra Baluja and Swati Oza, Fluid Phase Equilib., 2001, 178, 233. 
3. Ali A, Nain A K and Kamil M, Thermochim.Acta, 1996, 274, 209.

4. $\quad$ Manisha Gupta and Shukla J P, Indian J Pure Appl Phys., 1996, 34, 772.

5. Pankaj and Sharma C, Ultrasonics, 1991, 29, 344.

6. Velmurugan s, Nambinarayanan T K, Srinivasa Rao A and Krishnan B, Indian J Phys., 1987, 61B, 105.

7. Suryanarayana C V, J Acoust Soc Ind., 1983, 13, 11.

8. Fletcher A, J Phys Chem., 1969, 73, 2217.

9. Pimental G C and Maclellan A L, The Hydrogen Bond, (WH Freeman and Co, San Fransisco) 1960.

10. Hobbs M E and Bates WW, J Am Chem Soc., 1952, 74, 746.

11. Lin W and Tsay S J, J Phys Chem., 1970, 74, 1037.

12. Kannappan A N, Kesavasamy R and Ponnuswamy V, ARPN Journal of Engineering and Applied. Sciences, 2008, 3, 41.

13. Shanthi N, Ultrasonic velocity, free volume and internal pressure of liquids and liquid mixtures. Ph.D. Thesis, 1998, Annamalai University.

14. Jacobson B, Acta Chem Scand.,1952, 6,1485.

15. Rajendran V and Marikani, Acoustics Lett., UK, 1994, 18, 90. 


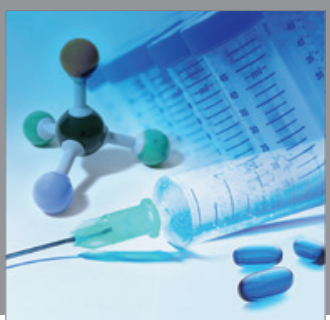

International Journal of

Medicinal Chemistry

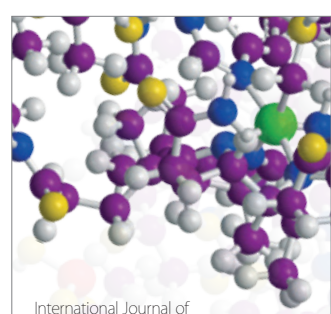

Carbohydrate Chemistry

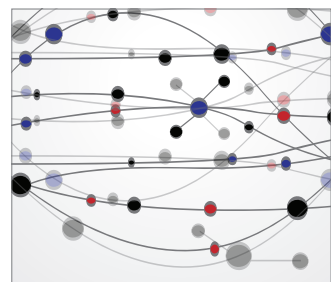

The Scientific World Journal
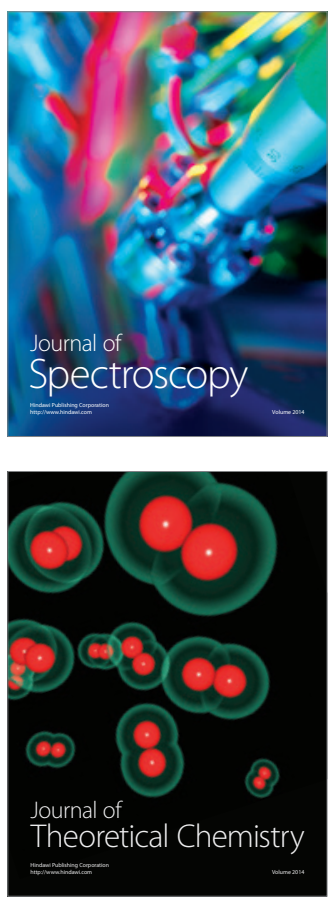
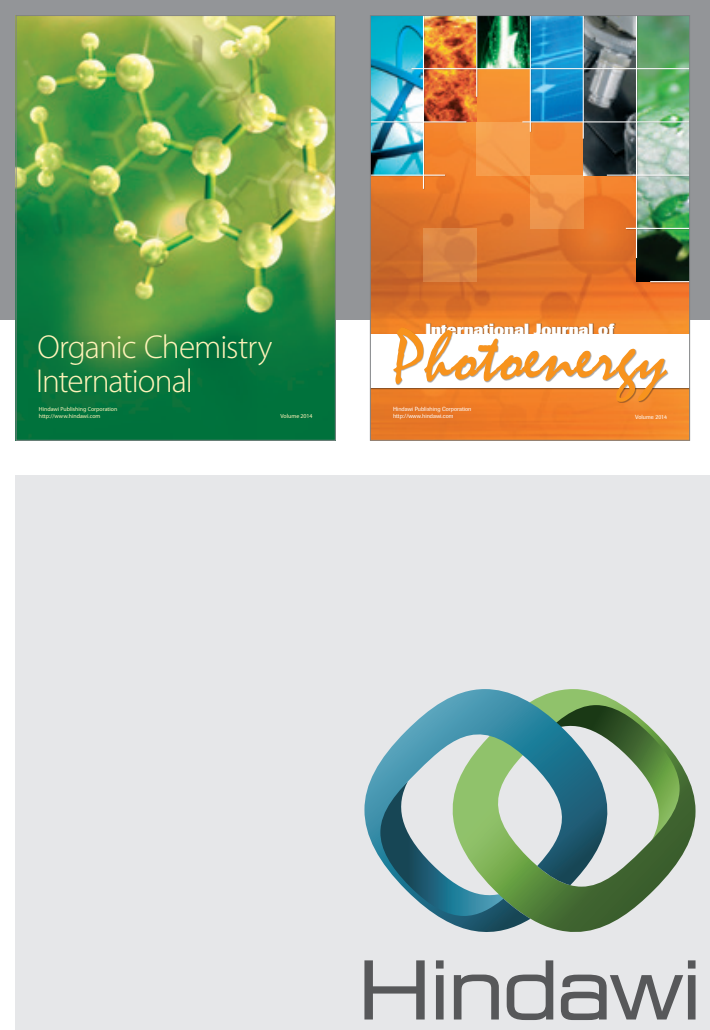

Submit your manuscripts at

http://www.hindawi.com
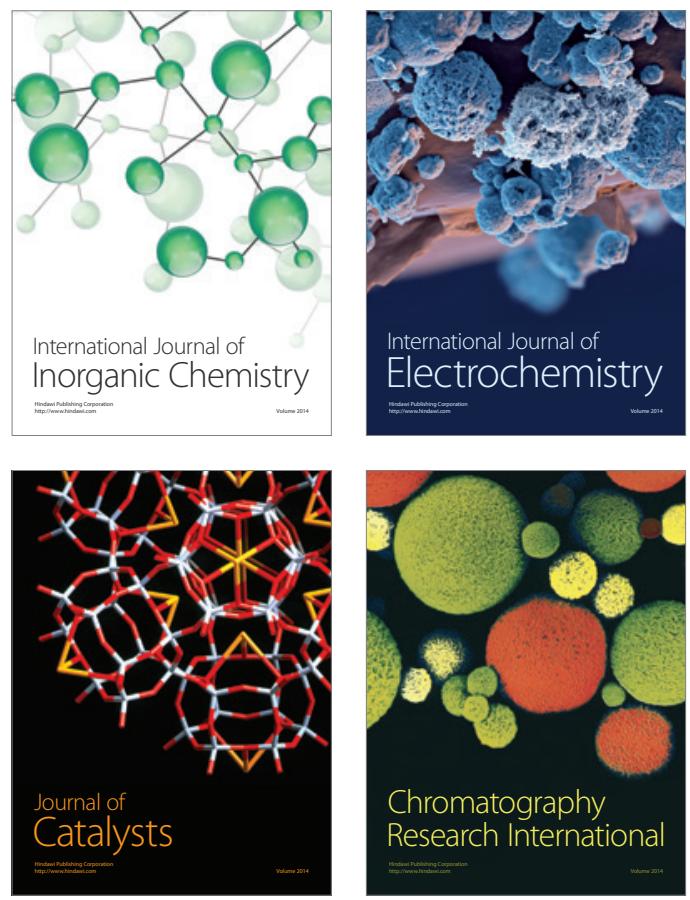
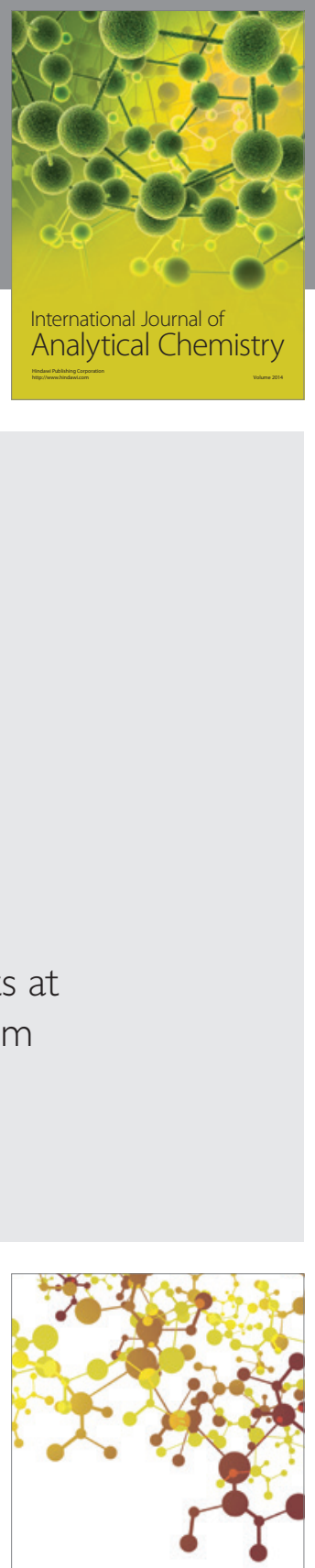

Journal of

Applied Chemistry
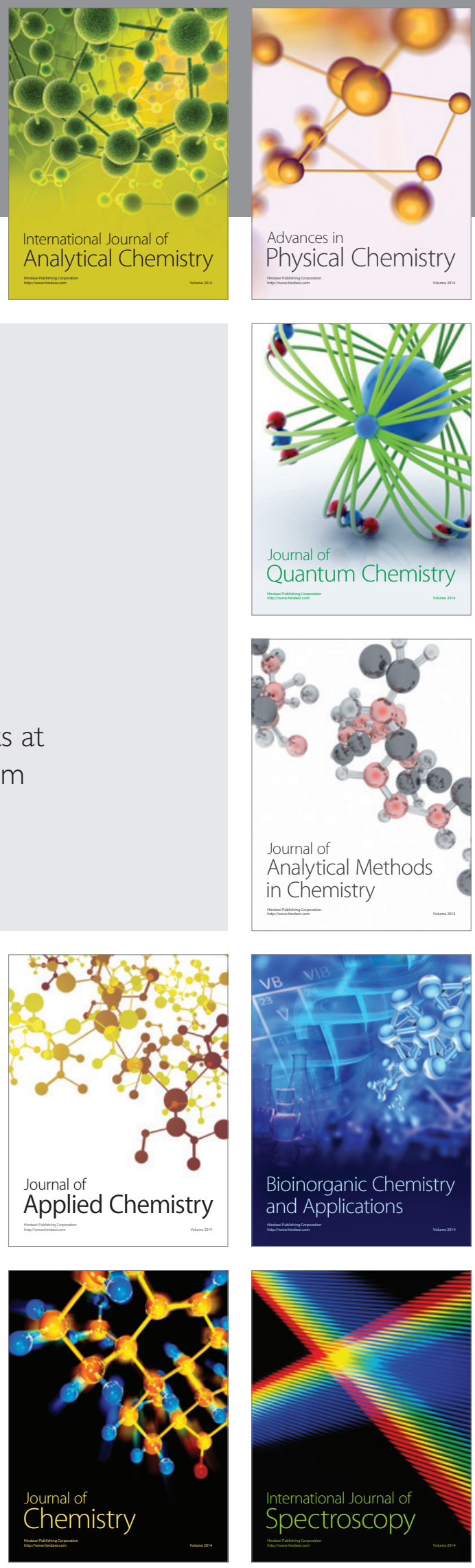